\title{
Sleep Quality and Social Support in People over 65 Years Old Who Have Had a Quarantine Process Due to Covid-19.
}

\author{
Gulay Dasdemir Ilkhan ${ }^{1}$, Hakan Celikhisar ${ }^{2}$, and Selen Ilhan Alp ${ }^{3}$ \\ ${ }^{1}$ Tire Public Hospital \\ ${ }^{2}$ Izmir Metropolitan Municipality Esrefpasa Hospital \\ ${ }^{3}$ Namik Kemal Universitesi - Degirmenalti Kampusu
}

November 9, 2020

\begin{abstract}
Background and Aim: We aimed to investigate the effects of anxiety or social support on sleep quality in patients with COVID19 who were older than 65 years of age and undergoing quarantine process. Material and Method: The study included the patients [?]65 years of age who had a quarantine process for 14 days during the COVID-19 outbreak. The sociodemographic features and comorbidities were recorded in all patients. Geriatric Anxiety Scale (GAS), Multidimensional Perceived Social Support Scale (SS), and Pittsburgh Sleep Quality Index (PSQI) questionnaires were applied. Results: Totally 198 patients (123 male and 75 female) were included in the study. Among patients, 115 (58.1\%) patients were living in a nursing home. All GAS scores and the total PSQI were significantly higher and all SS scores were significantly lower in PCR positive patients compared with the negative ones (p:0.001). Moreover, All GAS scores and the total PSQI were significantly higher and all SS scores were significantly lower in patients living in nursing homes compared with the others (p:0.001). Conclusion: In elderly patients faced with the COVID-19, social support was negatively associated with the sleep disturbances. We suggest that, increasing social support is important in elderly patients in the clash against COVID-19.
\end{abstract}

Sleep Quality and Social Support in People Over 65 Years Old Who Have Had a Quarantine Process Due to Covid-19

*Dasdemir Ilkhan Gulay, MD

Orcid No: 0000-0001-6453-3867

Okmeydanı Trainning and Research Hospital, Chest Diseases Clinic

Darulaceze Cad. No:25, 34384 /Sisli/Istanbul-Turkey

Tel: +902123145555

E-mail:gdasdemir1111@gmail.com

Association membership: European Respiratory Society

${ }^{*}$ Correponding author

Celikhisar Hakan, MD

Orcid No: 0000-0002-0109-3208

Izmir Metropolitan Municipality Hospital, Chest Diseases Clinic

Gaziler Caddesi No:315, 35110 Izmir-Turkey 
Tel: +902322938000

E- mail:hcelikhisar@gmail.com

Association membership: European Respiratory Society

Alp Ilhan Selen MD

Orcid No:0000-0003-2146-4712

Namık Kemal University SHMYO Child development

Kampüs Caddesi, No:1 Süleymanpaşa-Tekirdağ

GSM: +90505 2326457

E-mail:selenilhan@gmail.com

\section{Hosted file}

Sleep Quality and Social Support in People over 65 Years 0ld Who Have Had a Quarantine Process Due to C available at https://authorea.com/users/367441/articles/491793-sleep-quality-and-socialsupport-in-people-over-65-years-old-who-have-had-a-quarantine-process-due-to-covid-19

\section{Hosted file}

Tables.pdf available at https://authorea.com/users/367441/articles/491793-sleep-quality-andsocial-support-in-people-over-65-years-old-who-have-had-a-quarantine-process-due-tocovid-19 